\title{
Avaliação da tenacidade de concretos reforçados com fibras através de ensaios com sistema aberto
}

\author{
Toughness evaluation of fiber reinforced \\ concrete using open-loop test
}

\author{
Renata Monte ${ }^{1}$, Guilherme Stoll Toaldo ${ }^{1}$,
} Antonio Domingues de Figueiredo ${ }^{1}$

\author{
${ }^{1}$ Departamento de Engenharia de Construção Civil da Escola Politécnica da Universidade de São Paulo, São Paulo, SP \\ e-mail: renata.monte@poli.usp.br; guilherme.toaldo@usp.br; antonio.figueiredo@poli.usp.br
}

\begin{abstract}
RESUMO
A qualidade das estruturas produzidas com o Concreto Reforçado com Fibras (CRF) depende fundamentalmente da existência de um método de controle de tenacidade confiável, econômico e compatível com modelos de dimensionamento existentes. O controle usual se dá através de ensaios de tração na flexão de vigas, necessitando de equipamento específico raramente encontrado em laboratórios de controle tecnológico do concreto. O Ensaio Barcelona Simplificado (EBS) surge como uma promissora alternativa de ensaio para o CRF, pois permite a extração de testemunhos e utiliza recursos disponíveis na maioria dos laboratórios. Este trabalho tem por objetivo comparar resultados obtidos através do EBS com o método de ensaio de prismas através da JSCE-SF4, que é o mais utilizado no Brasil, buscando estabelecer correlações entre as diferentes respostas destes ensaios. Foram utilizadas uma fibra de aço e uma de polipropileno, dosadas em três teores cada. Foram moldadas cinco vigas para o ensaio JSCE-SF4 e extraídos oito cilindros para o EBS. Desses ensaios obteve-se curvas carga versus deslocamento. A correlação de resultados foi obtida através da comparação da energia necessária para provocar uma abertura de fissura equivalente nos dois métodos. Os resultados mostraram que o sistema aberto para controle de velocidade compromete ambos os ensaios, principalmente para baixos teores de fibras e no estado limite de serviço (ELS). Os ensaios EBS e JSCE-SF4 são correlacionáveis quanto à tenacidade e a resistência residual (pós-fissuração), possibilitando a utilização de um ou outro sem comprometimento da avaliação destas características. O EBS é de mais fácil execução e possibilita a avaliação da tenacidade em testemunhos de estruturas executadas.
\end{abstract}

Palavras-chave: Ensaio Barcelona, tenacidade, concreto reforçado com fibras, métodos de ensaio.

\section{ABSTRACT}

The quality control of the structures elements produced with Fiber Reinforced Concrete (FRC) depends critically of a test method to control toughness that could be considered reliable, economical and compatible with existing design models. The usual control is mainly based on bending tests of beam specimens, requiring specific equipment rarely found in Brazilian concrete control laboratories. The simplified Barcelona test (EBS) appears as a promising alternative test for FRC, as it allows the extraction of sample and uses resources available in most laboratories. This study aims to compare results obtained with the EBS method and the bending of beams through JSCE-SF4, which is the most used in Brazil, seeking to establish correlations between the different responses of these test method. One type of steel fiber and another polypropylene fiber were used with three levels of consumptions. Five beams were molded for test JSCE-SF4 and eight cylinders were extracted from the prisms edges for the EBS. These methods resulted load versus displacement curves. The correlations were obtained by comparing the energy required to cause a crack width equivalent for both methods. The results showed that the open-loop system turns difficult to measure the residual strength (poscracking) at Serviceability Limit States (SLS). The EBS and JSCE-SF4 test methods are correlated in terms of residual strength and toughness. These correlations allow the use of either method without compromising the evaluation of these characteristics. EBS is an easier test method to perform and allows the evaluation of toughness in cores extracted in real structural elements. 
MONTE, R; TOALDO, G.S.;FIGUEIREDO, A.D., revista Matéria, v.19, n.02, pp. 132-149, 2014.

Keywords: Barcelona test, toughness, fiber reinforced concrete, test method.

\section{INTRODUÇÃO}

O concreto reforçado com fibras (CRF) é um material compósito caracterizado pelo acréscimo de resistência residual à tração pós-fissuração, devido ao mecanismo de reforço das fibras que servem de ponte de transferência de tensões através das fissuras [1]. Além das vantagens técnicas há vantagens econômicas relacionadas, principalmente, à redução de etapas do processo produtivo e de mão de obra, garantindo maior velocidade e produtividade ao processo [2]

As vantagens desse material, aliado aos crescentes estudos na área podem ser responsáveis por um aumento significativo do uso do CRF para fins estruturais. No entanto, para garantir a qualidade dessa aplicação, é fundamental a existência de um método de controle de tenacidade que seja confiável, econômico e compatível com modelos de dimensionamento.

A maioria dos métodos de ensaio utilizada atualmente para caracterização do CRF é através da flexão de vigas. Como exemplo, podem ser citados os ensaios especificados pelas normas JSCE-SF4 (1984) []], ASTM C1609 (2010) [4], EN 14651 (2007) [5]], entre outros. O fato de se utilizar de corpos de prova prismáticos nestes ensaios praticamente impossibilita a extração de testemunhos para avaliar as propriedades mecânicas de estruturas já executadas, especialmente no caso de dúvidas com relação ao desempenho do CRF. Além disso, os métodos de ensaio, com exceção do previsto na JSCE-SF4, indicam a utilização de máquinas de ensaio com sistema fechado (closed-loop), ou seja, o controle da velocidade de ensaio é feito pela deflexão ou abertura de fissura do corpo de prova. Esse tipo de controle possibilita um ensaio mais estável, sem a ocorrência de instabilidades pós-fissuração da matriz []].

O Ensaio Barcelona normalizado pela UNE 83515 (2010) [7] surge como uma promissora alternativa, pois utiliza corpos de prova cilíndricos e de dimensões bem menores, permitindo a extração de amostras de estruturas, inclusive. Contudo, a norma especifica um extensômetro para medida do aumento do perímetro do corpo de prova ou TCOD (total circumferential opening displacement). $\mathrm{O}$ uso deste extensômetro resulta numa limitação para o ensaio, pois se trata de um equipamento caro e incomum na maioria dos laboratórios. Neste sentido, foi proposto por PUJADAS et al. (2013) [్] um ensaio Barcelona simplificado, no qual um modelo converte o deslocamento vertical da prensa no TCOD, eliminando a necessidade do uso do extensômetro. Isto torna o ensaio possível de ser realizado utilizando os recursos disponíveis nas máquinas universais dos laboratórios brasileiros, inclusive aquelas produzidas no Brasil.

Este artigo visa realizar um estudo para a avaliação dos procedimentos de controle do concreto reforçado com fibras (CRF), focando fundamentalmente na determinação da sua tenacidade através de ensaios com sistema aberto. Mais especificamente, este artigo tem por objetivo fornecer uma ferramenta de comparação do EBS com o ensaio JSCE-SF4, visto que este último é o mais difundido no meio técnico que também serve de referência para vários projetistas.

\section{MÉTODOS DE ENSAIO PARA DETERMINAÇÃO DA TENACIDADE}

\subsection{Ensaio Barcelona Simplificado - EBS}

O ensaio Barcelona consiste no duplo puncionamento de um corpo de prova cilíndrico de diâmetro $150 \mathrm{~mm}$, para corpos de prova moldados, ou no mínimo $100 \mathrm{~mm}$, para testemunhos extraídos, com relação entre o diâmetro e a altura igual a um [7]. O puncionamento é feito a partir de discos de carga com diâmetro de 1/4 do diâmetro do corpo de prova e altura de 1/5 da altura do corpo de prova, dispostos nas faces deste [7]. A carga deve ser aplicada de forma uniforme com velocidade de descida do equipamento de $0,5 \mathrm{~mm} / \mathrm{min}$.

Na configuração original do Ensaio Barcelona proposta na norma UNE 83515 (2010) [7] deve ser medido o aumento do perímetro do cilindro através de um extensômetro de circunferência (Figura 1), porém, conforme foi explicado anteriormente, trata-se de um equipamento caro que limita o campo de aplicação do ensaio. Dessa forma, foi proposto o EBS (Figura 2), no qual ao invés de medir o aumento do perímetro do cilindro (TCOD), mede-se apenas o deslocamento vertical da prensa. 


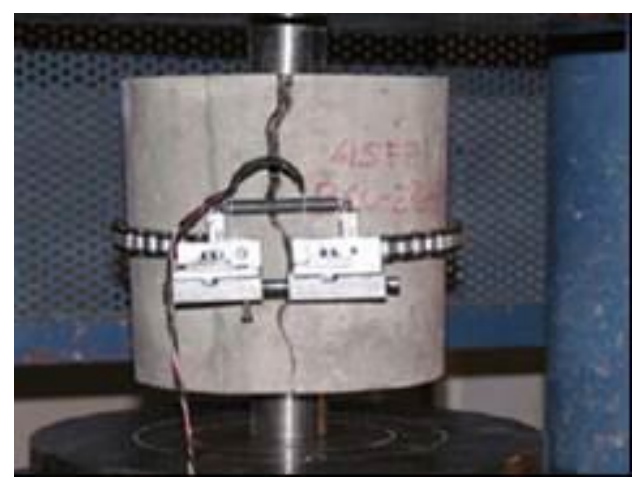

Figura 1: Ensaio Barcelona (MOLINS et al, 2009) [10].

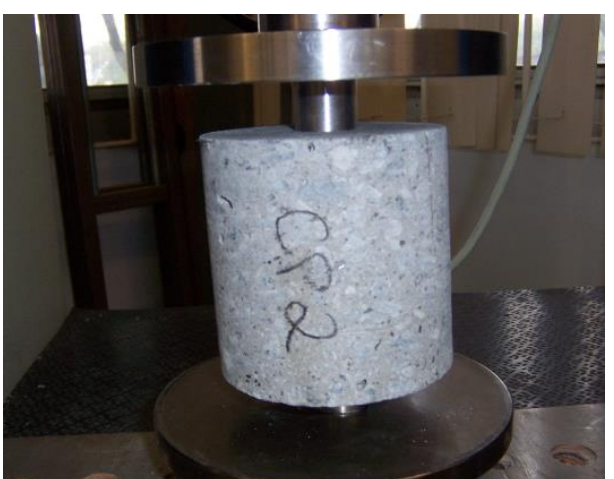

Figura 2: Ensaio Barcelona simplificado (EBS).

A configuração do EBS é viabilizada através da utilização de um modelo que converte o deslocamento vertical da prensa em TCOD, tendo sido validado experimentalmente com um erro inferior a 6,7\% [8].

O método basicamente separa o ensaio em três diferentes estágios e, para cada um deles, utiliza-se uma equação a fim de converter os deslocamentos. Essas equações utilizam como parâmetros grandezas que podem ser observadas ou medidas do corpo de prova, além da força e o seu correspondente deslocamento de dois pontos específicos: o ponto de carga máxima e o de início da resistência residual, esses pontos encontram-se ilustrados na Figura 3.
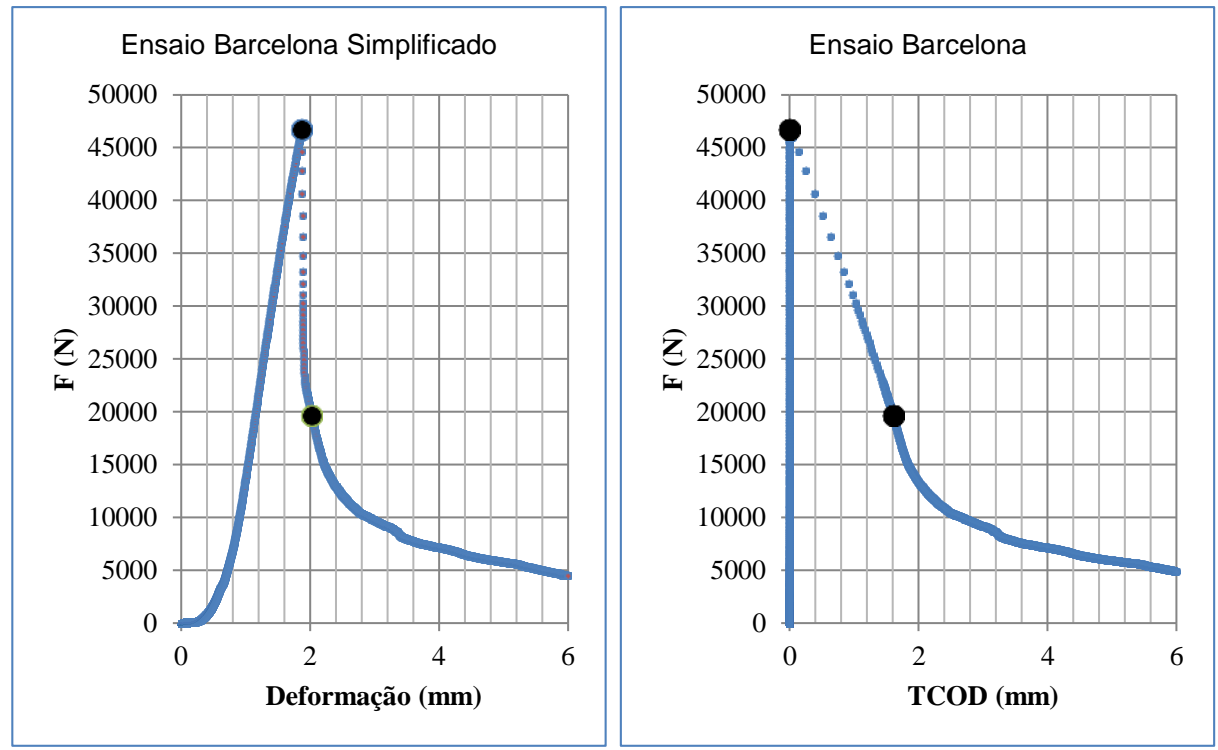

Figura 3: Conversão do ensaio Barcelona simplificado (esquerda) para o ensaio Barcelona (direita).

As equações utilizadas para esta conversão foram as seguintes:

$$
\begin{aligned}
& T C O D=0 \quad \delta \leq \delta_{c r} \\
& T C O D=n \times \frac{a \times \delta_{R, 0}}{2 \times l} \times \operatorname{sen} \frac{\pi}{n}\left(1-\frac{F}{F_{c r}}\right) \quad \delta_{c r}<\delta<\delta_{R, 0} \\
& T C O D=n \times \frac{a}{2 \times l} \times \operatorname{sen} \frac{\pi}{n} \times\left[\delta-\delta_{c r}+\delta_{R, 0} \times\left(1-\frac{F_{R, 0}}{F_{c r}}\right)\right] \quad \delta \geq \delta_{R, 0}
\end{aligned}
$$


Onde: n: número de fissuras radiais formadas no ensaio;

a: diâmetro da cunha;

1: comprimento da cunha;

F: Carga no ponto calculado;

Fcr, $\delta c r:$ Carga e deslocamento do ponto de carga máxima;

FR,0, $\delta$ R,0: Carga e deslocamento do ponto de início da resistência residual.

Os valores adotados para os parâmetros foram:

$\mathrm{n}=3$, seguindo a hipótese de modo de ruptura em 3 planos.

$1=26,81 \mathrm{~mm}$, este valor deve ser observado nos corpos de prova, porém, muitas vezes a obtenção deste valor pode não ser fácil. Dessa forma, o valor de $26,81 \mathrm{~mm}$ foi calculado em função do diâmetro do disco de aplicação da carga e do ângulo de atrito.

$\mathrm{a}=25 \mathrm{~mm}$, diâmetro do disco de carga utilizado no ensaio.

\subsection{Ensaio JSCE - SF4}

Existem diversos métodos de ensaio para se avaliar a tenacidade dos CRF, entretanto, nenhum ainda é normalizado no Brasil. Utilizam-se, em geral, ensaios de flexão de prismas como, por exemplo, o ensaio especificado na norma JSCE-SF4 (1984) [3] , que é o método de determinação da tenacidade mais empregado no Brasil, que também é o de concepção mais simples []].

Trata-se de um ensaio realizado em prismas carregados segundo quatro cutelos com uso de um LVDT para medida do deslocamento vertical no meio do vão (Figura 4).

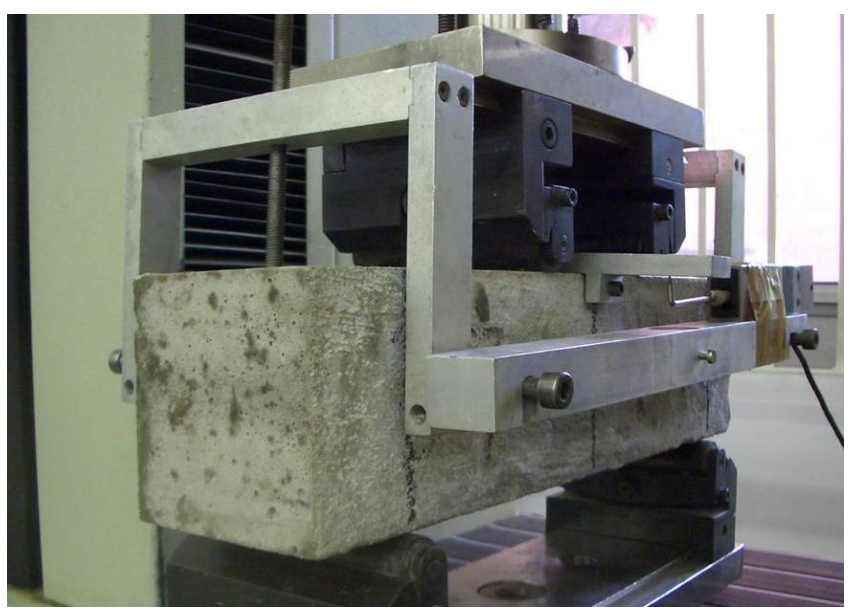

Figura 4: Configuração do ensaio JSCE-SF4.

A variável de controle do ensaio é a velocidade de deslocamento da prensa variando entre 0,15 e 0,5 $\mathrm{mm}$ por minuto. Dessa forma, o procedimento de ensaio permite o uso de controle tipo open-loop, no qual a velocidade de deslocamento mantida constante é a do equipamento e não a do corpo de prova. Com isto o ensaio que pode estar sujeito a instabilidade pós-pico, ao contrário do que aconteceria se fosse realizado com um sistema controle da velocidade de deslocamento fechado [9]. A instabilidade pode ser identificada pelo aumento da separação dos pontos no gráfico de carga versus deslocamento.

\subsection{Correlação entre os ensaios EBS e JSCE-SF4}

O raciocínio que guiou a correlação dos resultados dos dois ensaios foi obter a energia necessária para provocar uma determinada abertura de fissura. As aberturas das fissuras dos ensaios EBS e JSCE-SF4 devem ser compatibilizadas, pois se tratam de ensaios de natureza diferentes. Enquanto um mede o deslocamento vertical da prensa de um corpo cilíndrico, o outro mede o deslocamento no meio do vão de uma viga.

Esta ferramenta foi apresentada por MOLINS et al. (2009) [10], onde o autor obteve uma correspon- 
dência geométrica entre o ensaio Barcelona e o ensaio de flexão de vigas proposto na norma belga NBN B $15-238$ (1992) [11]. Os autores concluem que o deslocamento vertical medido no ensaio de flexão de viga $(\delta)$ e a abertura total das fissuras no ensaio de puncionamento de cilindro (TCOD) estão correlacionados na proporção $2: 1$.

Dada a similaridade entre este último ensaio e o JSCE - SF4 (utilizado nesta pesquisa) seguiu-se a mesma linha de raciocínio e obteve-se uma correspondência entre o Ensaio Barcelona e o ensaio japonês. O procedimento é apresentado a seguir.

Utilizando os ensaios EBS e JSCE-SF4 com as correspondências apresentadas, foi desenvolvido o programa experimental que será detalhado a seguir.

\section{MATERIAIS E MÉTODOS}

O programa experimental consistiu em uma matriz de concreto reforçada com duas fibras, uma de aço e uma de polipropileno, em três teores cada uma, totalizando doze composições. Os concretos reforçados com fibras foram produzidos nas mesmas condições e moldados corpos de prova para realização dos ensaios de compressão axial, EBS e JSCE-SF4.

\subsection{Materiais empregados}

Os materiais utilizados nos concretos foram cimento Portland CP II-F-32, areia artificial e pedrisco. A areia tem dimensão máxima característica de 4,8 mm e módulo de finura 2,93. O pedrisco tem dimensão máxima característica de $9,5 \mathrm{~mm}$.

A Tabela 1 apresenta a média de três determinações da massa específica de cada material, medidas em um picnômetro à gás hélio.

Tabela 1: Massa específica dos materiais utilizados na pesquisa.

\begin{tabular}{c|c}
\hline MATERIAL & MASSA ESPECÍFICA $\left(\mathbf{g} / \mathbf{c m}^{3}\right)$ \\
\hline Areia Artificial & 2,684 \\
\hline Pedrisco & 2,656 \\
\hline Cimento & 3,009 \\
\hline
\end{tabular}

A norma NBR 15530 (2007) [12] estabelece ensaios e requisitos para a caracterização de fibras de aço. Nesta norma são avaliados os parâmetros de tolerância dimensional, defeitos de fabricação, resistência à tração e dobramento. Com isso, procura-se garantir que o produto fornecido esteja em conformidade com estes requisitos, proporcionando um desempenho adequado ao concreto reforçado com fibras.

As fibras poliméricas não são contempladas na norma brasileira, o que dificulta a padronização do mercado deste tipo de fibras. Assim, a caracterização dimensional da fibra de polipropileno foi feita utilizando os procedimentos da norma de fibra de aço.

A fibra de aço utilizada nessa pesquisa (Figura 5a) é classificada como A-I (tipo A - ancoragem nas extremidades; classe I - oriunda de arame trefilado a frio). As fibras A-I são especificadas pelo diâmetro equivalente (de) e comprimento total ( () . O fator de forma $(\lambda)$ é obtido através da razão $\ell / d e$.

A fibra de polipropileno utilizada (Figura 5b) é composta de macrofibra estrutural monofilamento, produzida com $100 \%$ de copolímero de polipropileno virgem e uma fração fibrilada para o controle da retração. 


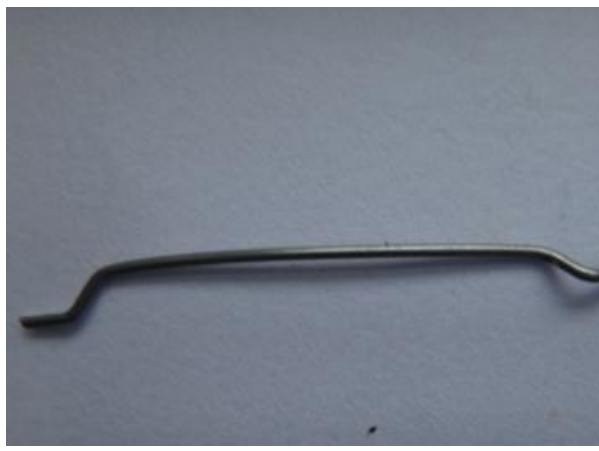

(a)

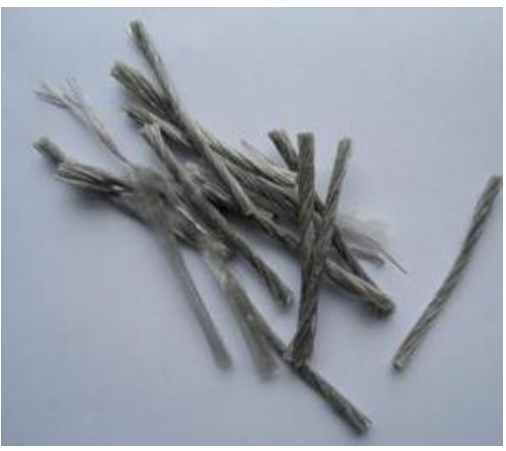

(b)

Figura 5: a) Fibra de aço utilizada; b) Fibra de polipropileno utilizada.

Uma amostra de 60 fibras de cada uma foi coletada para caracterização geométrica utilizando um paquímetro digital. Na Tabela 2 são apresentados os resultados médios e os valores nominais apresentados pelos fabricantes.

Tabela 2: Resultados das características dimensionais das fibras, valores nominais dos fabricantes e tolerâncias da NBR 15530 para fibras de aço.

\begin{tabular}{l|c|c|c|c|c|c}
\hline \multirow{2}{*}{ FIBRA } & \multicolumn{3}{|c|}{ RESULTADOS MÉDIOS MEDIDOS } & \multicolumn{3}{c}{ VALORES NOMINAIS DOS FABRICANTES } \\
\cline { 2 - 7 } & $\mathbf{d}_{\mathbf{e}}(\mathbf{m m})$ & $\boldsymbol{\ell}(\mathbf{m m})$ & $\boldsymbol{\lambda}$ & $\mathbf{d}_{\mathbf{e}}(\mathbf{m m})$ & $\boldsymbol{\ell}(\mathbf{m m})$ & $\boldsymbol{\lambda}$ \\
\hline Aço & 0,61 & 29,07 & 47,59 & 0,67 & 30 & 45 \\
\hline Polipropileno & 0,29 & 53,44 & 190,83 & $0,34 *$ & 54 & 158 \\
\hline $\begin{array}{l}\text { Tolerâncias } \\
\text { NBR 15530 }\end{array}$ & $\pm 5 \%$ & $\pm 10 \% * *$ & $>40$ & & \\
\hline
\end{tabular}

*Calculado em função dos valores nominais de comprimento e fator de forma.

**Fibras com comprimento maior que $35 \mathrm{~mm}$ a tolerância para o comprimento é de $5 \%$.

Considerando as tolerâncias dimensionais apresentadas na norma NBR 15530 (2007) [12] a fibra de aço utilizada pode ser considerada aprovada. Já a fibra de polipropileno não poderia ser considerada aprovada se as tolerâncias fossem as mesmas aplicadas às fibras de aço, indicando que um estudo específico para proposição de critérios adequados as caracteristicas deste tipo de fibra.

Uma amostra de 10 fibras de aço foi coletada para o ensaio de dobramento e todas as fibras foram consideradas aprovadas segundo os critérios da norma [12]. Além disso, uma amostra de 200 gramas desta fibra foi coletada para avaliação de defeitos (ausência de ancoragem, emendas de topo ou oxidação superficial de difícil remoção), apresendendo defeitos em quantidade inferior ao limite estabelecido pela norma.

\subsection{Produção dos concretos}

Os concretos foram produzidos a partir de uma matriz com proporção em massa de materiais secos de 1:1,57:1,96 e relação água/cimento igual a 0,60. Nesta matriz foram adicionadas as duas fibras dosadas em três teores em volume, proporcionados em relação ao volume de concreto produzido.

A fim de obter uma equivalência de desempenho para as duas fibras, utilizou-se o dobro do teor em volume da fibra de polipropileno em relação à de aço, de acordo com os estudos apresentados por Figueiredo et al. (2012) [13]. Os teores utilizados encontram-se na Tabela 3.

Tabela 3: Teores de fibras utilizados.

\begin{tabular}{c|c|c|c}
\hline \multicolumn{2}{c|}{ FIBRA DE AÇO } & \multicolumn{2}{c}{ FIBRA DE POLIPROPILENO } \\
\hline $\mathbf{k g} / \mathbf{m}^{\mathbf{3}}$ & $\boldsymbol{\%}$ & $\mathbf{k g} / \mathbf{m}^{\mathbf{3}}$ & $\boldsymbol{\%}$ \\
\hline 20 & 0,25 & 4,6 & 0,50 \\
\hline
\end{tabular}


MONTE, R; TOALDO, G.S.;FIGUEIREDO, A.D., revista Matéria, v.19, n.02, pp. 132-149, 2014.

\begin{tabular}{l|l|l|l}
\hline 30 & 0,375 & 6,8 & 0,75 \\
\hline 45 & 0,50 & 9,1 & 1,00 \\
\hline
\end{tabular}

Os concretos foram produzidos em betoneira iniciando pela mistura dos agregados e parte da água por 2 minutos. Em seguida a betoneira foi desligada para a colocação do cimento e, com a betoneira ligada, o restante da água foi adicionado e a mistura realizada por mais 3 minutos. Por fim as fibras eram adicionadas lentamente com a betoneira em movimento, deixando misturar por mais 2 minutos após o término da colocação das fibras.

Após a mistura dos concretos foram moldados 2 corpos de prova cilíndricos para determinação da resistência à compressão, 5 corpos de prova prismáticos de 10x10x40 $\mathrm{cm}$ para o ensaio JSCE-SF4 e 2 corpos de prova prismáticos de $15 \times 15 \times 55 \mathrm{~cm}$ para extração de 8 testemunhos cilíndricos para o ensaio Barcelona simplificado. Os corpos de prova foram desmoldados no dia seguinte e mantidos em câmara úmida (95\%) até os 27 dias de idade, ou seja, a véspera da idade de ensaio que foi de 28 dias.

\section{RESULTADOS E DISCUSSÕES}

\subsection{Resistência à compressão}

A Tabela 4 apresenta os resultados de resistência à compressão dos concretos, medida aos 28 dias.

Tabela 4: Resultados de resistência à compressão dos concretos aos 28 dias.

\begin{tabular}{|c|c|c|c|c|c|c|}
\hline FIBRA & $\begin{array}{c}\text { TEOR } \\
(\%)\end{array}$ & CP & $\begin{array}{c}\mathbf{f}_{\mathbf{c 2 2}} \\
(\mathrm{MPa})\end{array}$ & $\begin{array}{c}\mathbf{f}_{\text {cm }} \\
(\mathbf{M P a})\end{array}$ & $\begin{array}{c}\text { DESVIO PADRÃO } \\
\text { (MPa) }\end{array}$ & $\begin{array}{c}\text { COEFICIENTE DE } \\
\text { VARIAÇÃAO }(\%)\end{array}$ \\
\hline \multirow{6}{*}{ Aço } & \multirow{2}{*}{0,25} & 1 & 35 & \multirow{6}{*}{34} & \multirow{6}{*}{1} & \multirow{6}{*}{3} \\
\hline & & 2 & 32 & & & \\
\hline & \multirow{2}{*}{0,375} & 1 & 33 & & & \\
\hline & & 2 & 36 & & & \\
\hline & \multirow{2}{*}{0,5} & 1 & 34 & & & \\
\hline & & 2 & 34 & & & \\
\hline \multirow{6}{*}{ Polipropileno } & \multirow{2}{*}{0,5} & 1 & 27 & \multirow{6}{*}{28} & \multirow{6}{*}{1} & \multirow{6}{*}{5} \\
\hline & & 2 & 25 & & & \\
\hline & \multirow{2}{*}{0,75} & 1 & 28 & & & \\
\hline & & 2 & 29 & & & \\
\hline & \multirow{2}{*}{1} & 1 & 28 & & & \\
\hline & & 2 & 29 & & & \\
\hline
\end{tabular}

Observa-se que os concretos produzidos com fibra de polipropileno resultaram menor resistência à compressão, quando comparados aos com fibras de aço. Isto já foi observado por TIGUMAN (2004) [14] que indicou que a fibra de polipropileno, devido a sua baixa resistência, pode atuar como um defeito no interior do concreto, reduzindo sua resistência mecânica à compressão. Verifica-se também que a resistência à compressão não foi significativamente alterada em função do aumento do teor de fibras e que a variabilidade foi baixa, independente de ser fibra de aço ou de polipropileno.

\subsection{Ensaio de flexão JSCE-SF4 e ensaio Barcelona simplificado}

O comportamento pós-fissuração dos concretos foi avaliado através de dois ensaios já detalhados anteriormente, o ensaio de flexão de vigas pelo método JSCE-SF4 e o ensaio Barcelona simplificado (EBS). Este último foi convertido para o ensaio Barcelona através das equações apresentadas no item 2.2, sendo que os resultados apresentados já são após a conversão.

As Figuras 6 e 7 apresentam os resultados destes ensaios para o teor de 0,25\% de fibras de aço. 
MONTE, R; TOALDO, G.S.;FIGUEIREDO, A.D., revista Matéria, v.19, n.02, pp. 132-149, 2014.

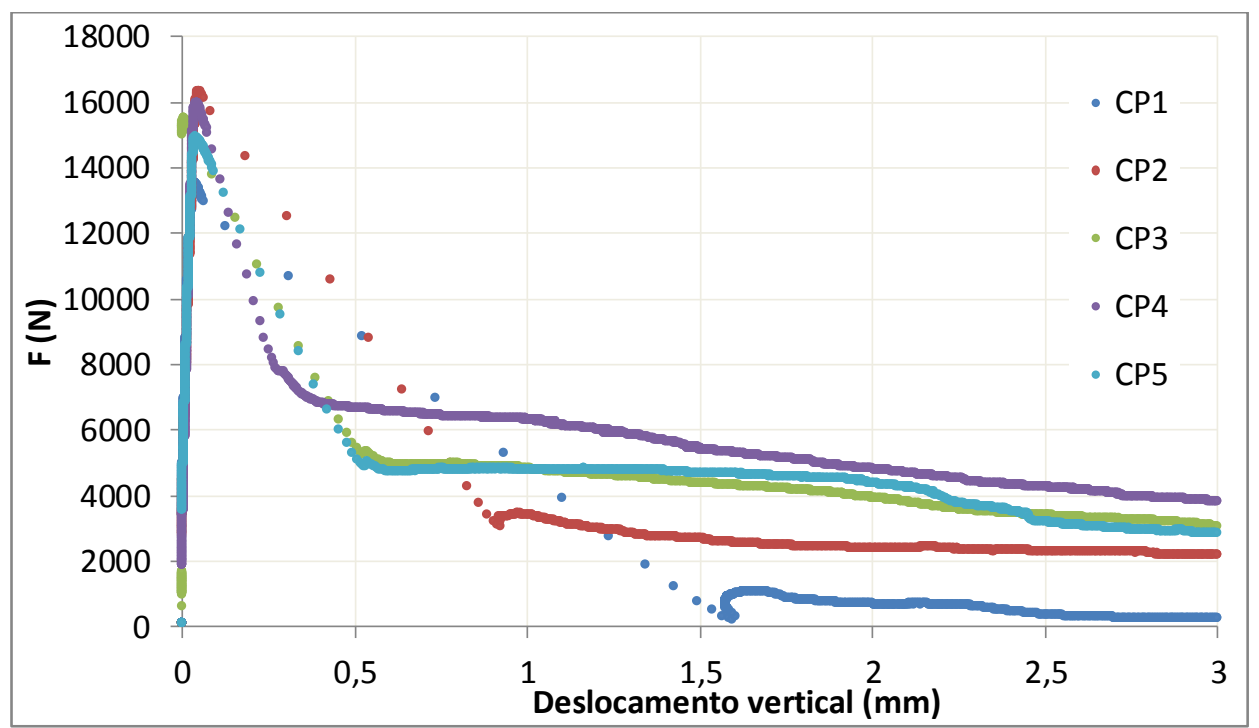

Figura 6: Resultados dos ensaios JSCE - SF4 para o teor de $0,25 \%$ de fibra de aço.

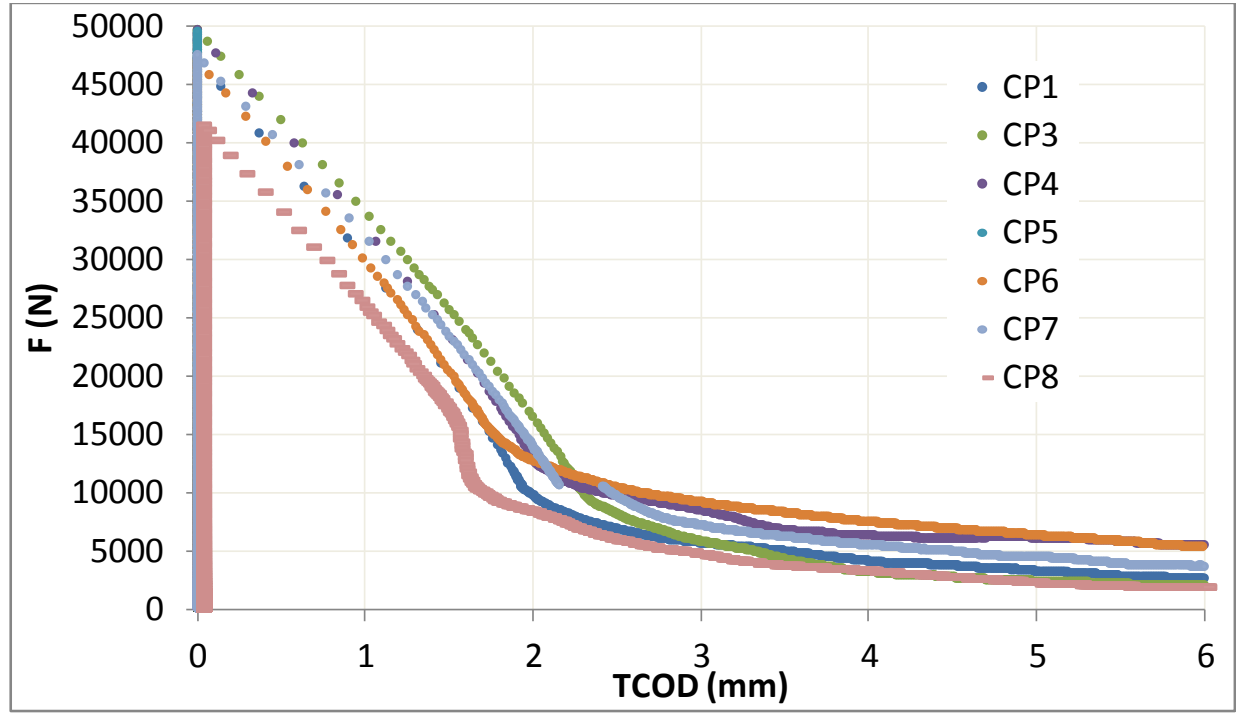

Figura 7: Resultados dos ensaios EBS para o teor de 0,25\% de fibra de Aço.

Observa-se na Figura 6 que o ensaio JSCE-SF4 apresenta elevada instabilidade, quando comparado ao ensaio Barcelona apresentado na Figura 7. A instabilidade é evidenciada pela distância entre os pontos dos gráficos logo após a ruptura da matriz, que é menos nas curvas do ensaio EBS. O aumento no teor de fibras diminui este efeito, como pode ser visto nas Figuras 8 e 9, onde são apresentados os resultados dos concretos reforçados com $0,375 \%$ de teor de fibra de aço. 
MONTE, R; TOALDO, G.S.;FIGUEIREDO, A.D., revista Matéria, v.19, n.02, pp. 132-149, 2014.

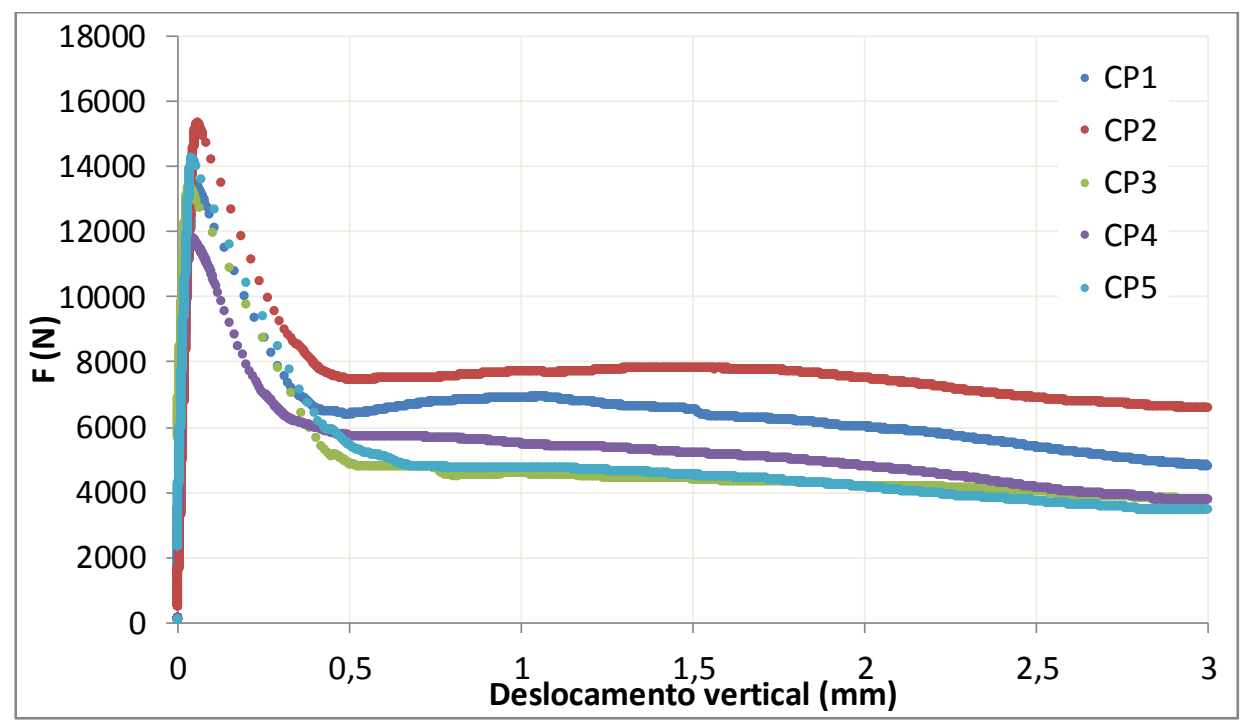

Figura 8: Resultados dos ensaios JSCE - SF4 para o teor de 0,375\% de fibra de aço.

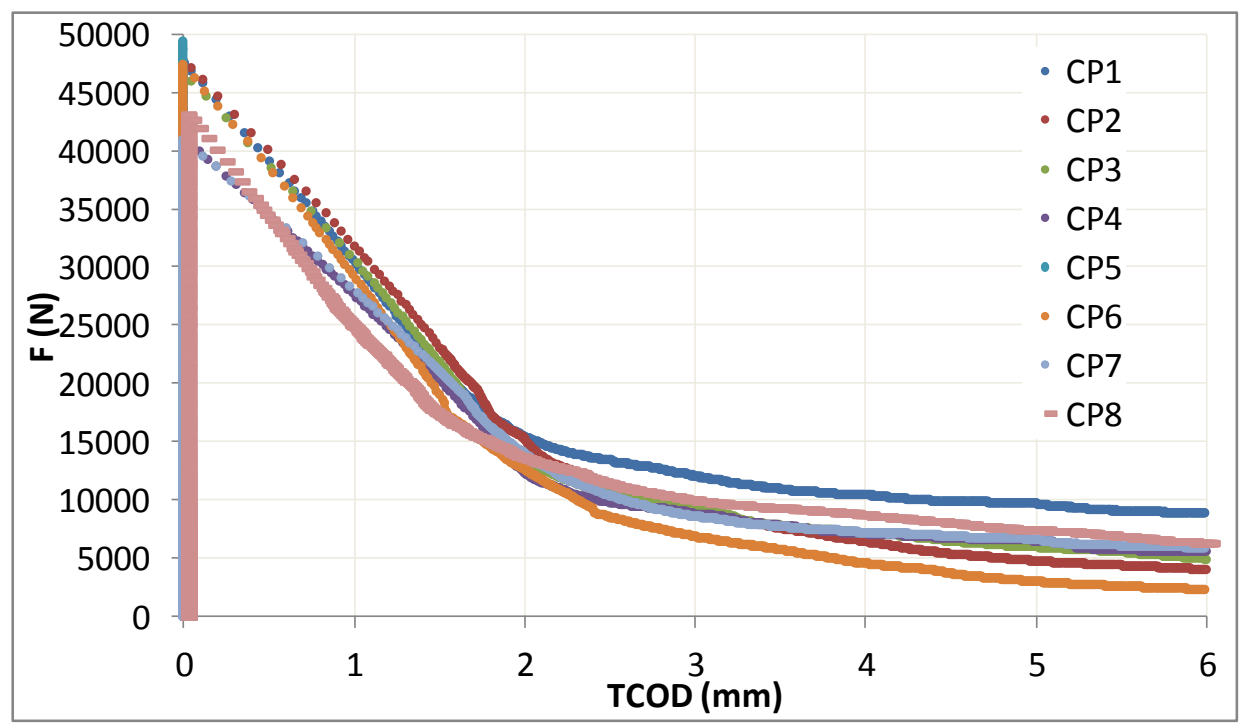

Figura 9: Resultados dos ensaios EBS para o teor de 0,375\% de fibra de Aço.

Verifica-se na Figura 8 que a instabilidade do ensaio JSCE-SF4 diminuiu com o aumento do teor de fibras de aço. O mesmo ocorreu com as curvas do ensaio EBS (Figura 9), cujo afastamento entre os pontos foi menor que o obtido no primeiro teor de fibras apresentado.

Os resultados com o maior teor de fibras de aço utilizado podem ser vistos nas Figuras 10 e 11. 
MONTE, R; TOALDO, G.S.;FIGUEIREDO, A.D., revista Matéria, v.19, n.02, pp. 132-149, 2014.

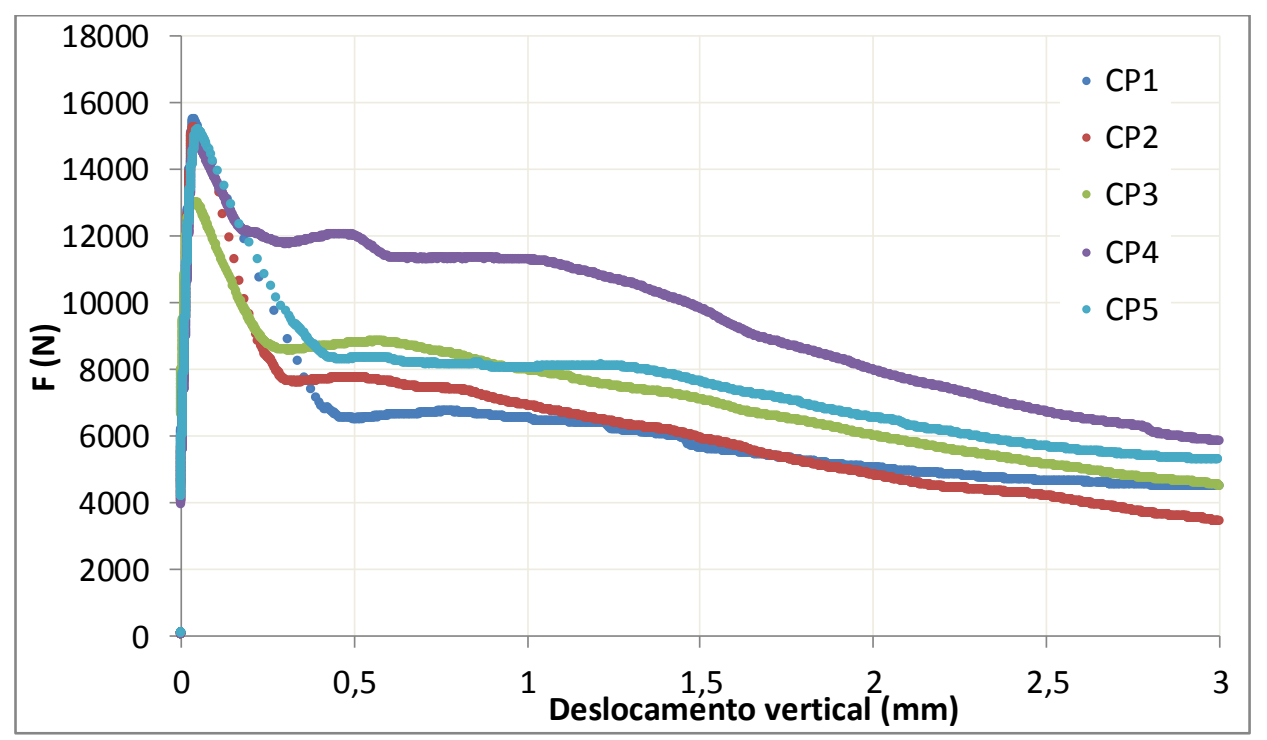

Figura 10: Resultados dos ensaios JSCE - SF4 para o teor de 0,50\% de fibra de aço.

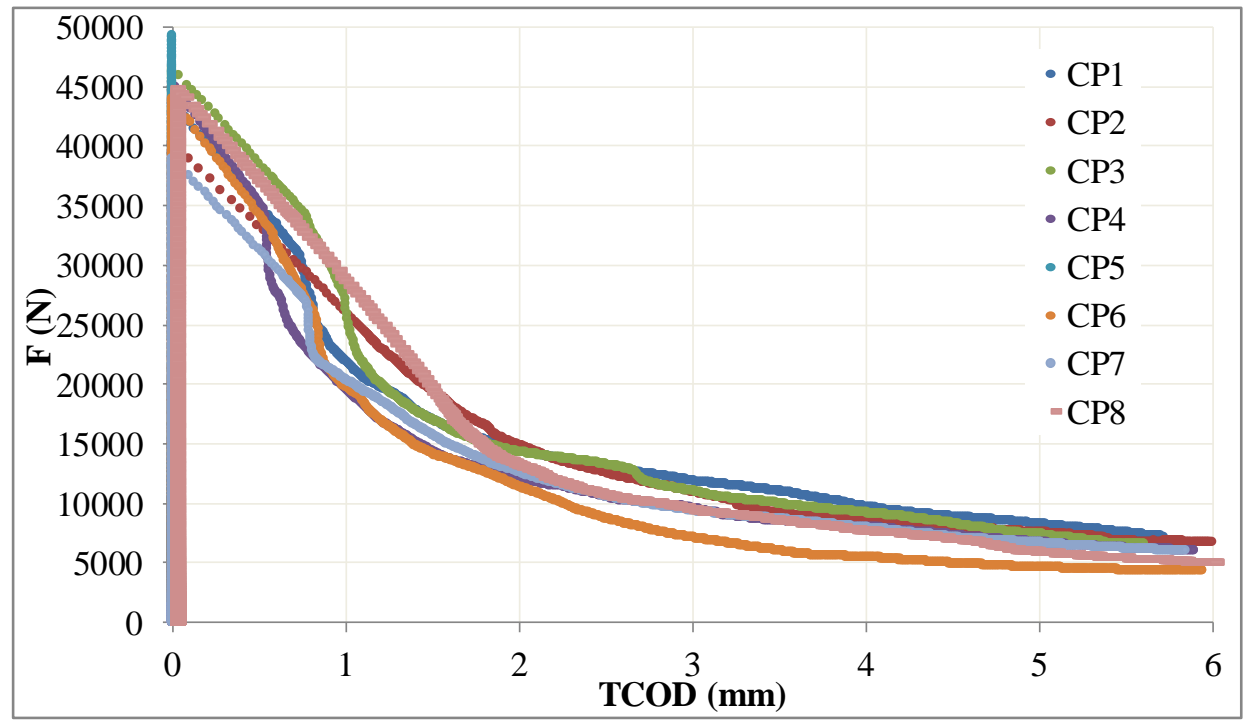

Figura 11: Resultados dos ensaios EBS para o teor de 0,50\% de fibra de Aço.

A instabilidade do ensaio JSCE-SF4 foi reduzida para o maior teor de fibras de aço, mas não eliminada em alguns corpos de prova e os resultados ainda foram muito dispersos como apresenta a Figura 10. No ensaio EBS observa-se que a instabilidade também foi reduzida com o acréscimo no teor de fibras, sendo identificada quando se compara as distâncias entre os pontos dos gráficos das Figuras 7, 9 e 11 que foram gradualmente ficando mais próximos no trecho pós-fissuração. Além disso, no ensaio JSCE-SF4 a variabilidade dos resultados, demonstrado pela diferença entre as curvas do diferentes corpos de prova, foi maior quando comparado ao ensaio EBS. Isto ocorre porque no ensaio de flexão de vigas a presença de um número maior ou menor de fibras na parte inferior da viga, onde a abertura da fissura é maior, exerce forte influencia na variabilidade do ensaio (Figura 12a). Já no caso do ensaio EBS a área de fissuração é maior, pois ocorrem entre 2 a 4 fissuras radiais, sendo menos influenciado por pequenas variações na presença de fibras nas sessões das fissuras (Figura 12b). 
MONTE, R; TOALDO, G.S.;FIGUEIREDO, A.D., revista Matéria, v.19, n.02, pp. 132-149, 2014.

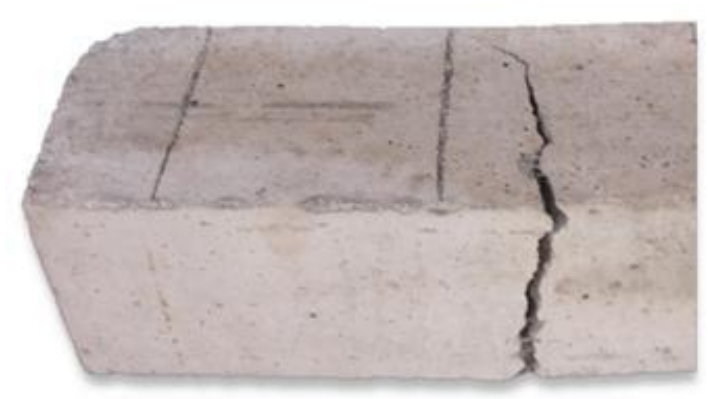

(a)

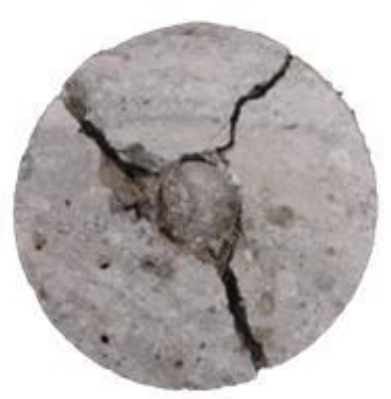

(b)

Figura 12: a) Abertura de uma fissura no ensaio de flexão de viga; b) Abertura de três fissuras no ensaio EBS.

Os resultados dos ensaios JSCE-SF4 e EBS com fibras de polipropileno serão apresentados a seguir. As Figuras 13 e 14 apresentam os resultados para o menor teor de fibra de polipropileno avaliado.

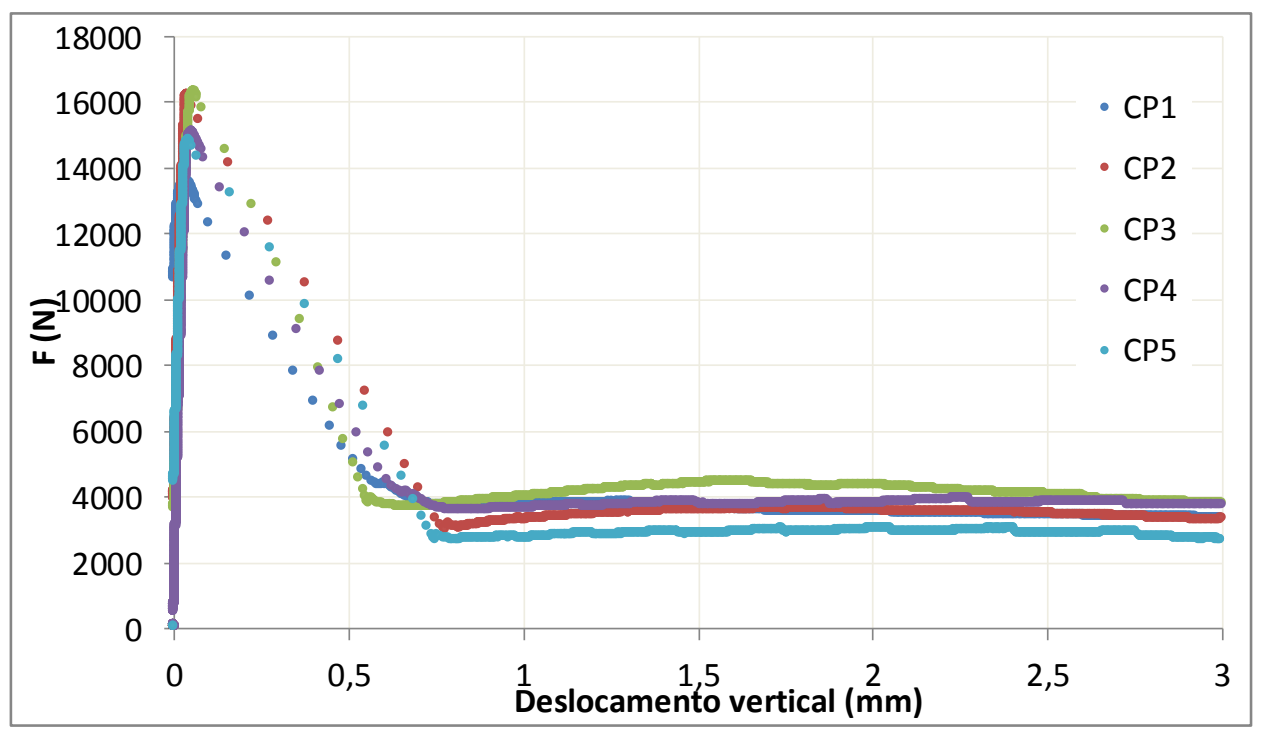

Figura 13: Resultados dos ensaios JSCE - SF4 para o teor de $0,50 \%$ de fibra de polipropileno. 
MONTE, R; TOALDO, G.S.;FIGUEIREDO, A.D., revista Matéria, v.19, n.02, pp. 132-149, 2014.

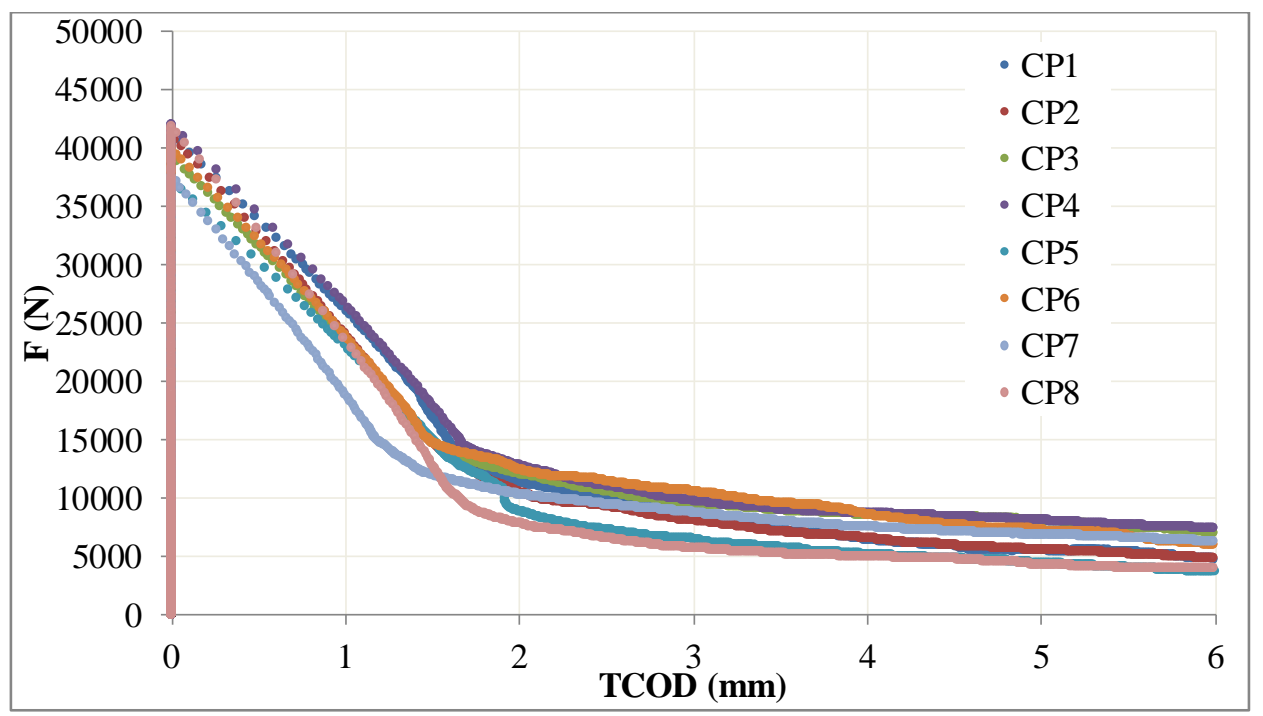

Figura 14: Resultados dos ensaios EBS para o teor de $0,50 \%$ de fibra de polipropileno.

De forma análoga ao observado com o menor teor da fibra de aço (metade do teor em volume em relação à fibra de polipropileno), a Figura 13 mostra intensa instabilidade nos resultados pós-fissuração da matriz para o ensaio JSCE-SF4. Contudo, as curvas de ensaio dos cinco corpos de prova foram muito mais próximas quando comparadas àquelas onde foram utilizadas as fibras de aço. Isto ocorre devido ao maior número de fibras presente na seção de ruptura, que é muito superior no caso da fibra de polipropileno. Além disso, observa-se que a carga residual foi mantida quase constante até o deslocamento de $3 \mathrm{~mm}$, podendo ser percebido um aumento de carga residual em algumas curvas. Isto deve-se ao desfibrilamento das fibras, que aumentam a capacidade de reforço conforme se aumenta o deslocamento (slip-hardening), comportamento oposto aos concretos com fibras de aço, nos quais a capacidade resistente foi sempre decrescente com o aumento do deslocamento (softening). Este resultado foi também observado de forma mais pronunciada na pesquisa de SALVADOR e FIGUEIREDO (2013) [9] , que utilizou o ensaio previsto na EN 14651 (2007) [] de flexão de vigas com entalhe em equipamento com sistema de controle fechado. No ensaio EBS (Figura 14) os resultados apresentaram menor instabilidade, mas apresentou comportamento de softening. A obtenção de comportamento de softening ou hardening para um mesmo compósito pode ser obtido dependendo do tipo de ensaio. Um compósito que apresenta softening em um ensaio de flexão de vigas pode apresentar hardening em um ensaio de placa, por exemplo.

As Figuras 15 e 16 apresentam os resultados com o teor intermediário de fibra de polipropileno. 
MONTE, R; TOALDO, G.S.;FIGUEIREDO, A.D., revista Matéria, v.19, n.02, pp. 132-149, 2014.

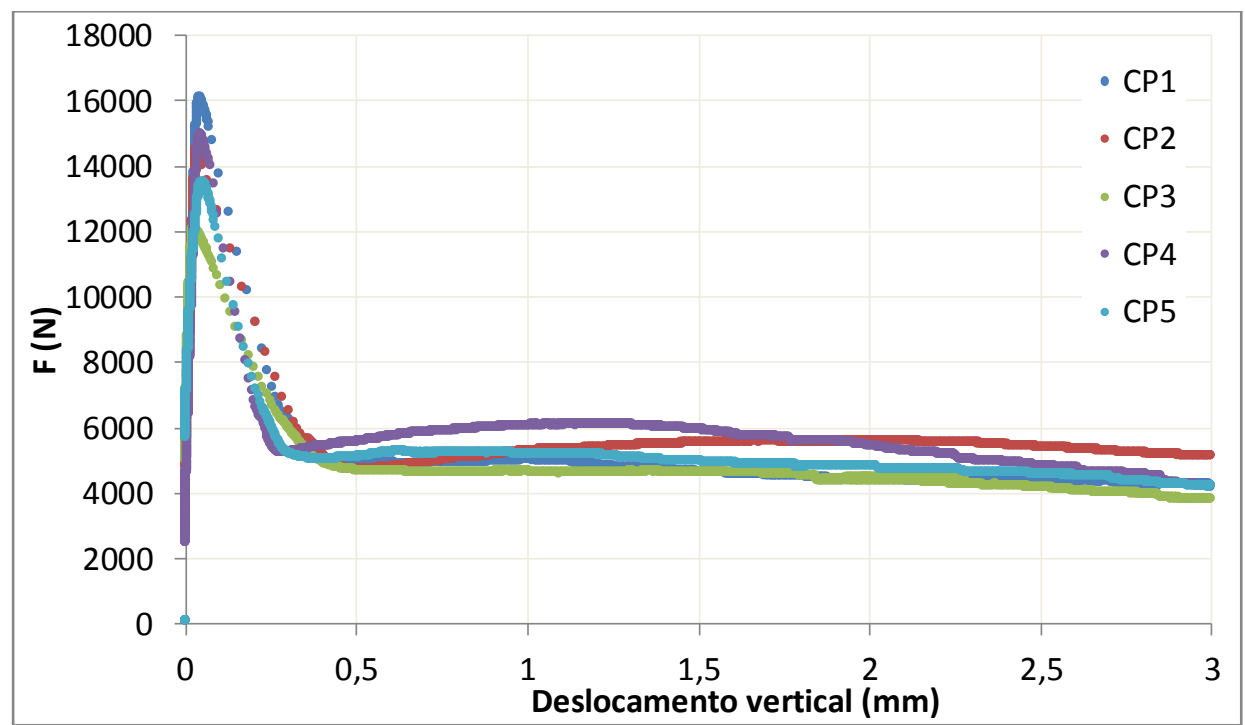

Figura 15: Resultados dos ensaios JSCE - SF4 para o teor de 0,75\% de fibra de polipropileno.

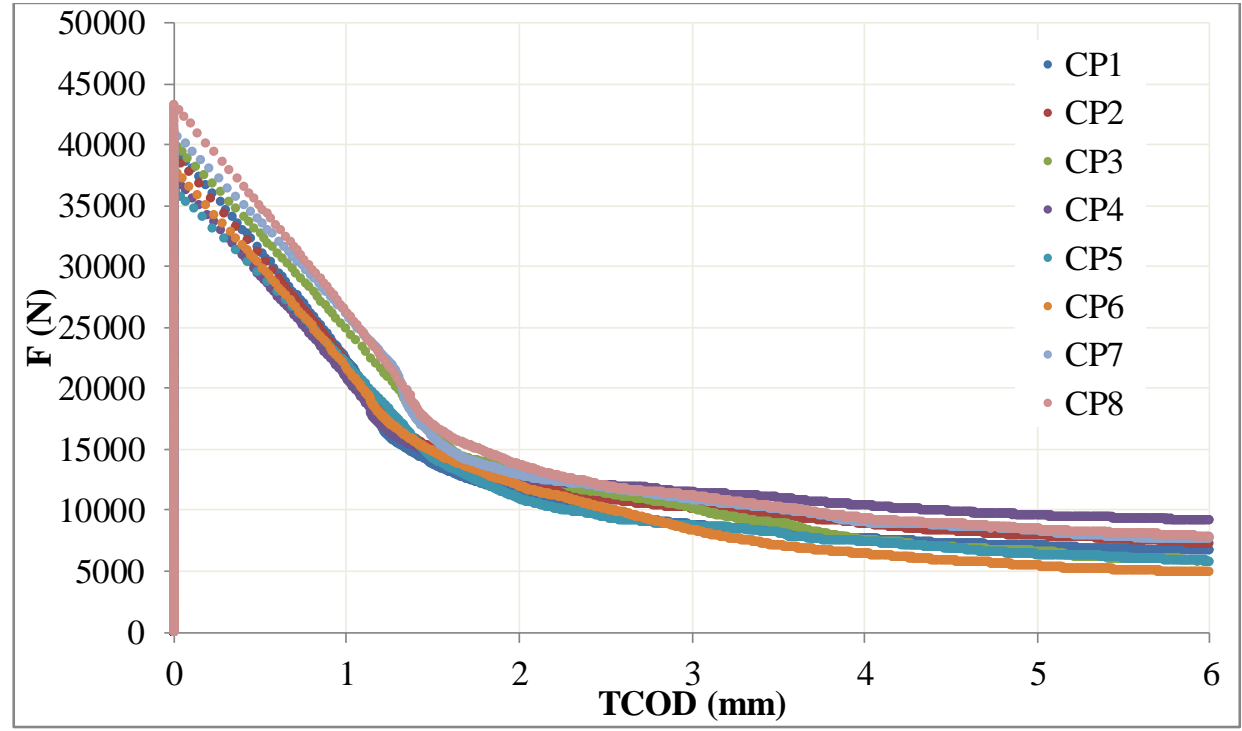

Figura 16: Resultados dos ensaios EBS para o teor de $0,75 \%$ de fibra de polipropileno.

Verifica-se na Figura 15 que o aumento no teor de fibras melhorou o comportamento pós-fissuração no ensaio JSCE-SF4, tornando-o menos instável e variável, e com menor comprometimento da análise em menores deslocamentos. O comportamento de slip-hardening foi mais evidente para este teor de fibra. Os resultados do ensaio EBS (Figura 16) apresentaram menor instabilidade e, mesmo com o aumento da quantidade de fibras, o comportamento de softening foi mantido. As Figuras 17 e 18 apresentam os resultados do maior teor de fibra de polipropileno empregado. 
MONTE, R; TOALDO, G.S.;FIGUEIREDO, A.D., revista Matéria, v.19, n.02, pp. 132-149, 2014.

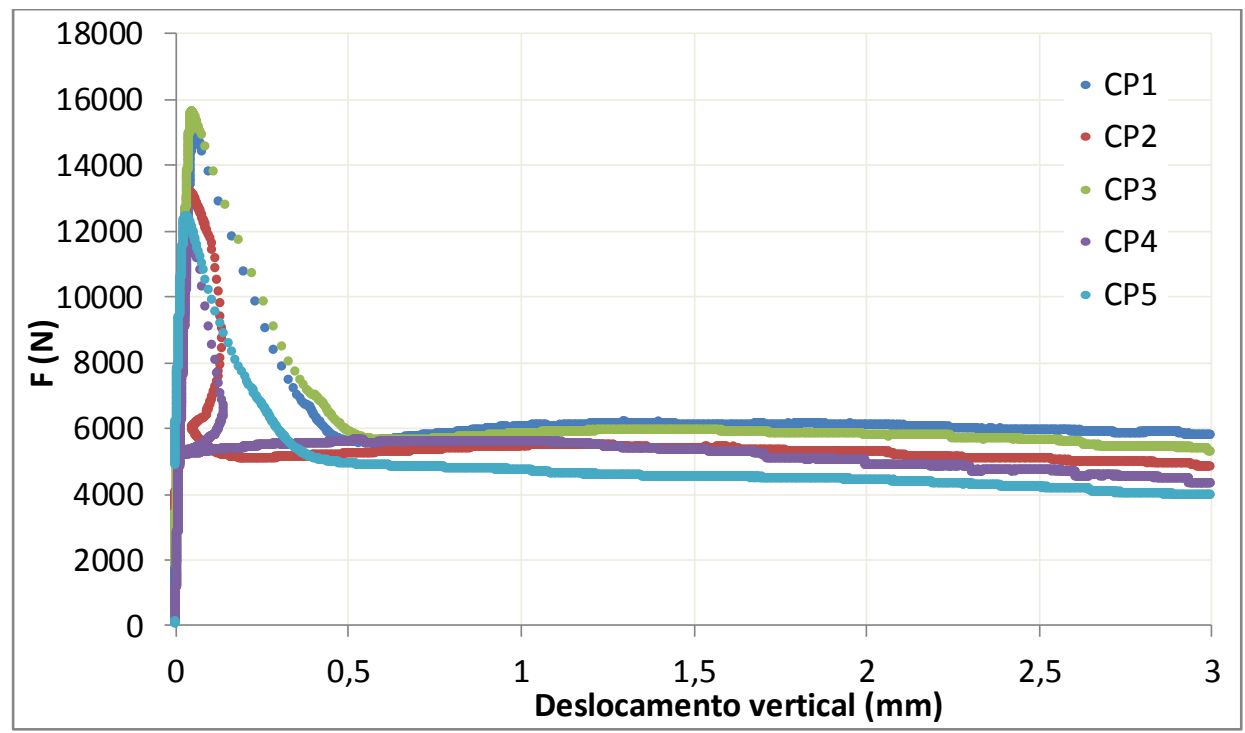

Figura 17: Resultados dos ensaios JSCE - SF4 para o teor de 1\% de fibra de polipropileno.

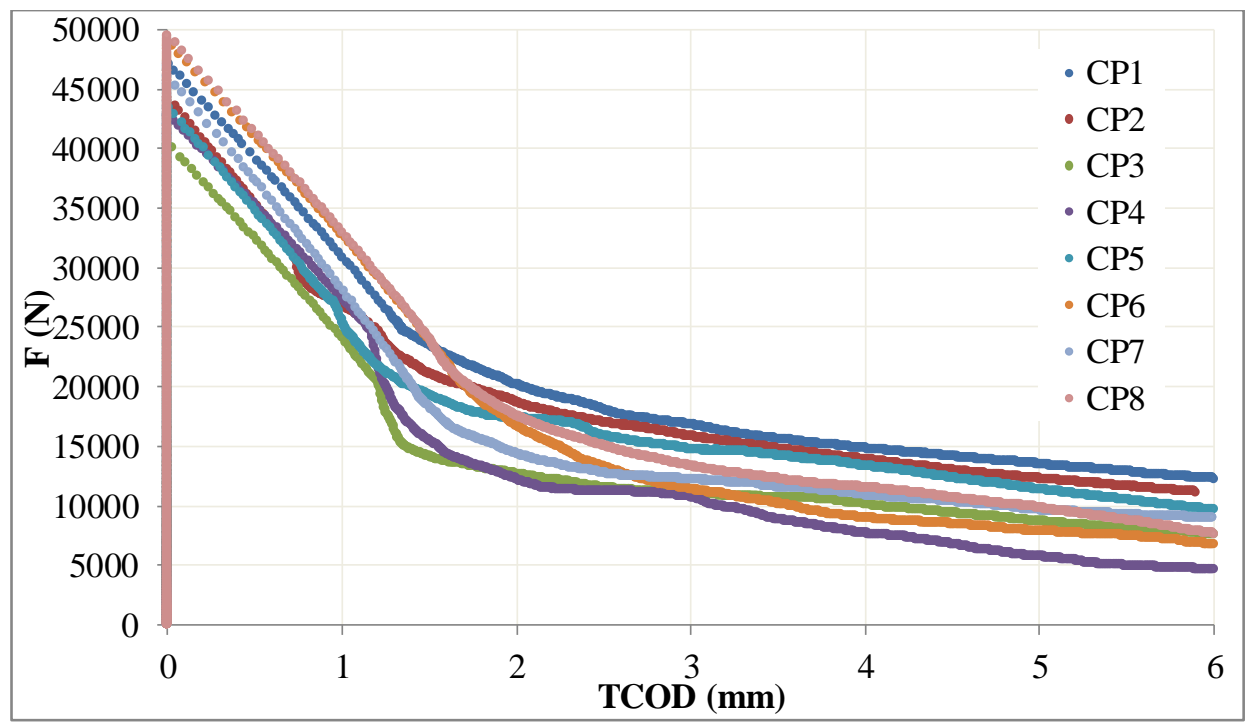

Figura 18: Resultados dos ensaios EBS para o teor de 1\% de fibra de polipropileno.

Observa-se na Figura 17 que mesmo para o maior teor de fibra de polipropileno empregado a instabilidade do ensaio JSCE-SF4 permanece, indicando que, com o uso de equipamento com sistema de controle aberto, a instabilidade é difícil de ser controlada. O ensaio EBS (Figura 18) apresentou pouca instabilidade, mas com maior dispersão nas curvas de ensaio quando comparados aos teores menores de fibras de polipropileno. Isto pode ser decorrência da homogeneização do concreto ter sido dificultada pela maior quantidade de fibras.

Para identificar a variabilidade dos métodos de ensaio foram analisadas as dispersões nas medidas de tenacidade e tensões residuais. Para o cálculo das tenacidades foram calculadas as áreas das curvas de carga versus deslocamento em N.m, para ambos os ensaios. A norma japonesa não apresenta critério para determinação das tensões residuais, assim foi adotado o procedimento da ASTM C 1609 (2010) [4] que determina as tensões residuais para deslocamentos L/600 $(0,5 \mathrm{~mm})$ e L/150 $(2 \mathrm{~mm})$, utilizando as equações 4 e 5 .

$$
f_{d, L / 600}=\frac{P_{d, L / 600} \cdot L}{b \cdot d^{2}}
$$




$$
f_{d, L / 150}=\frac{P_{d, L / 150} \cdot L}{b \cdot d^{2}}
$$

Onde: $f_{d, L / 600}$ e $f_{d, L / 150}$ são as resistências residuais, quando o deslocamento vertical for $L / 600$ e $L / 150$, respectivamente $(\mathrm{MPa})$;

$P_{d, L / 150}$ e $P_{d, L / 150}$ são as cargas residuais, quando o deslocamento vertical for $L / 600$ e L/150, respectivamente $(\mathrm{N})$;

Lé o vão de ensaio (mm);

b e d são a largura e altura do corpo de prova, respectivamente ( $\mathrm{mm}$ ).

Para o ensaio EBS foi utilizada a equação 6 apresentada na norma UNE 83515 (2010) [7], utilizando valores de TCOD iguais a $1 \mathrm{~mm}$ e $4 \mathrm{~mm}$ para manter a 2:1 indicada no item 2.3.

$$
f_{c t, T C O D}=\frac{4 \cdot P_{T C O D}}{9 \cdot \pi \cdot a \cdot H}
$$

Onde: $\mathrm{f}_{\mathrm{ct}, \mathrm{TCOD}}$ é a resistência residual à tração do concreto para um determinado TCOD (em MPa);

$\mathrm{P}_{\mathrm{Rx}}$ é a carga correspondente a um determinado TCOD (em N);

a é o diâmetro do disco de aplicação de carga (em mm);

H é a altura do corpo de prova (em $\mathrm{mm}$ ).

A variabilidade de cada um dos métodos de ensaio pode ser melhor caracterizada pelos resultados apresentados nas Tabelas 5 e 6.

Tabela 5: Tenacidades médias e coeficientes de variação para os ensaios JSCE-SF4 e EBS.

\begin{tabular}{l|c|c|c|c}
\hline & \multicolumn{2}{|c|}{ JSCE-SF4 } & \multicolumn{2}{c}{ EBS } \\
\cline { 2 - 5 } & $\begin{array}{c}\text { TENACIDADE MÉDIA } \\
(\mathbf{N . m})\end{array}$ & $\begin{array}{c}\text { COEFICIENTE DE } \\
\text { VARIAÇÃO }(\%)\end{array}$ & $\begin{array}{c}\text { TENACIDADE } \\
(\mathbf{N} . m)\end{array}$ & $\begin{array}{c}\text { COEFICIENTE DE } \\
\text { VARIAÇÃO (\%) }\end{array}$ \\
\hline Aço-0,25\% & 12,9 & 13 & 75,4 & 10 \\
\hline Aço-0,375\% & 13,2 & 16 & 77,1 & 6 \\
\hline Aço-0,5\% & 16,8 & 16 & 71,9 & 7 \\
\hline $\mathrm{PP}-0,5 \%$ & 11,4 & 5 & 65,2 & 8 \\
\hline $\mathrm{PP}-0,75 \%$ & 11,8 & 5 & 66,7 & 7 \\
\hline $\mathrm{PP}-1 \%$ & 12,7 & 9 & 84,7 & 10 \\
\hline
\end{tabular}

Verifica-se na Tabela 5 que as maiores dispersões no cálculo da tenacidade foram obtidas para as fibras de aço e para o ensaio JSCE-SF4, chegando a 16\%. Este valor, considerando o histórico desde tipo de ensaio, não é muito alto uma vez que o coeficiente de variação pode superar $20 \%$ com frequência como apontou MORGAN et al. (1995)[15]. O ensaio EBS apresentou valores de coeficientes de variação para o cálculo da tenacidade entre 6 e 10\%, valores inferiores aos obtidos por MOLINS et al. (2009) [10]. Cabe ressaltar que, considerando os valores de tenacidade e dispersão apresentados, apenas o concreto com maior teor de fibras de aço para o ensaio JSCE-SF4 e polipropileno para o ensaio EBS tiveram tenacidade significativamente maior, devido à instabilidade elevada nos menores teores superestimarem seus resultados. $\mathrm{O}$ cálculo da tenacidade é feito através da determinação da área sob a curva de carga por deslocamento. A ocorrência de instabilidade acaba gerando uma região de incerteza de resistência residual que terá uma influência muito grande especialmente para os menores deslocamentos correspondentes ao ELS. Quando ocorre a instabilidade há uma maior dificuldade de se diferenciar a resistência residual de concretos reforçados com baixo consumo de fibras principalmente. Para minimizar este efeito o calculo de tenacidade foi realizado para diferentes níveis de deflexão e TCOD, obtendo-se as correlações apresentadas nas Figuras 19 e 20. 
MONTE, R; TOALDO, G.S.;FIGUEIREDO, A.D., revista Matéria, v.19, n.02, pp. 132-149, 2014.

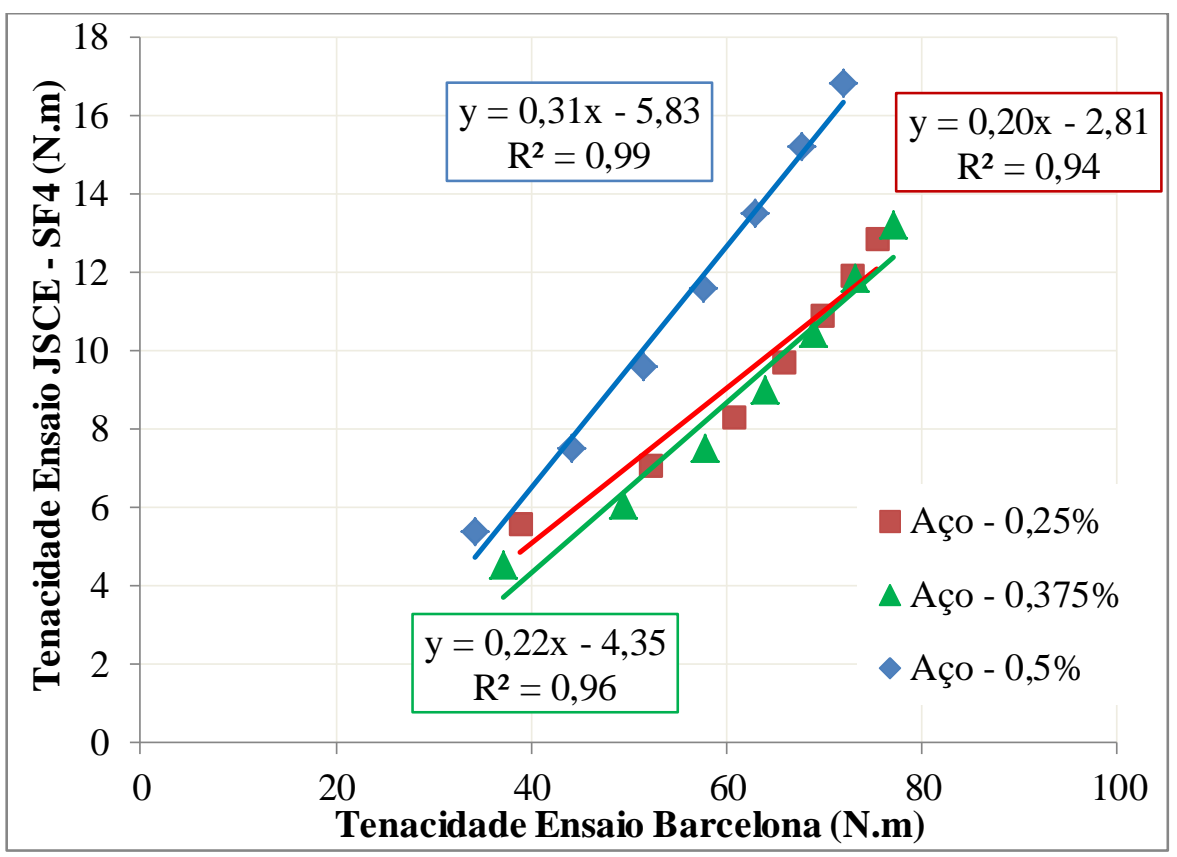

Figura 19: Regressões lineares entre as tenacidades médias dos ensaios JSCE-SF4 e EBS para a fibra de aço.

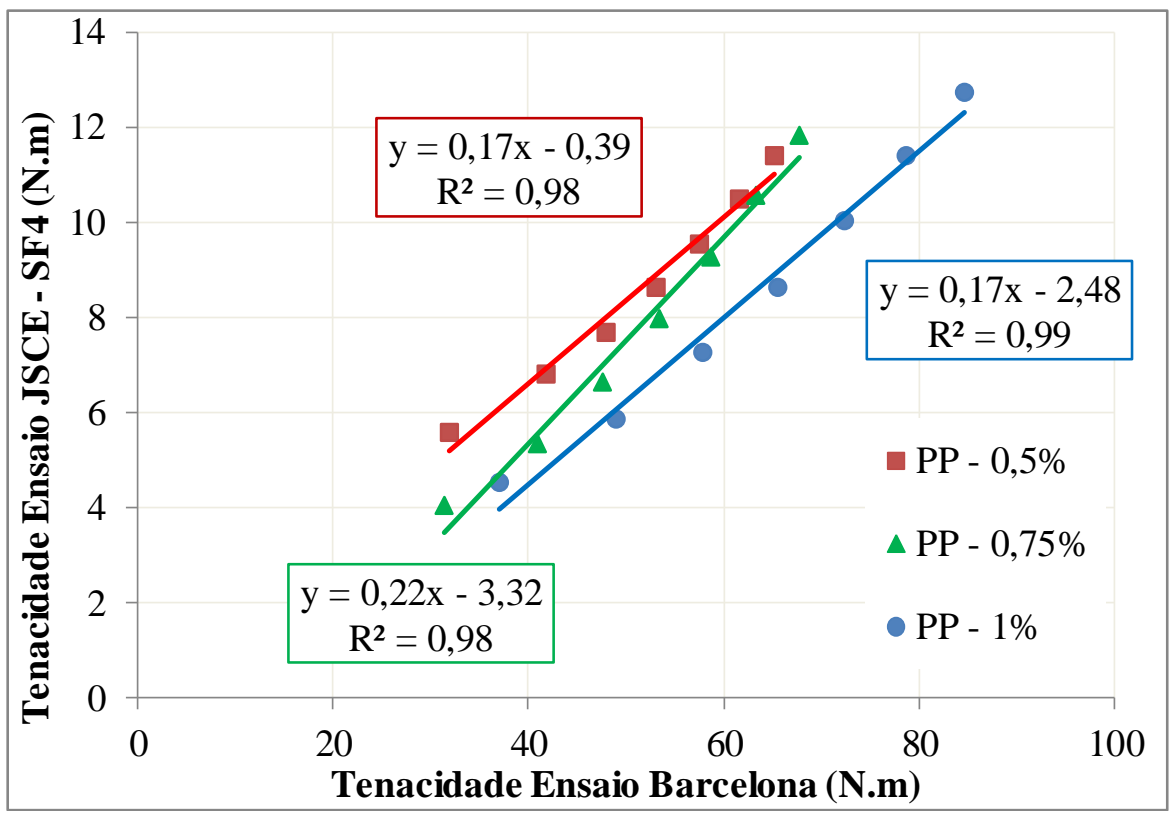

Figura 20: Regressões lineares entre as tenacidades médias dos ensaios JSCE-SF4 e EBS para a fibra de polipropileno.

Os elevados coeficientes de determinação $\mathrm{R}^{2}$ das regressões (acima de 0,94) apresentados nas Figuras 19 e 20 indicam ótima correlação entre as tenacidades calculadas pelos dois métodos. Este resultado foi similar ao obtido por MOLINS et al. (2009) [10], inclusive no coeficiente de inclinação da reta de regressão obtido por estes autores foi próximo a 0,30. É importante ressaltar que esta pesquisa utilizou tipos e teores de fibras diferentes, portanto esses resultados complementam uma validação mais ampla dessa correlação.

Outra alternativa para avaliar o potencial de reforço das fibras é calcular a resistência residual nos estados limites de serviço (ELS) e último (ELU), considerando a equivalência de deflexão e TCOD apresentada no item 2.3. A Tabela 6 apresenta a síntese dos resultados médios de resistências residuais obtidas e respectivos coeficientes de variação. 
MONTE, R; TOALDO, G.S.;FIGUEIREDO, A.D., revista Matéria, v.19, n.02, pp. 132-149, 2014.

Tabela 6: Resistências residuais para diferentes aberturas de fissuras nos ensaios JSCE-SF4 e EBS.

\begin{tabular}{|c|c|c|c|c|c|c|c|c|}
\hline & \multicolumn{4}{|c|}{ RESISTÊNCIAS RESIDUAIS - JSCE-SF4 } & \multicolumn{4}{|c|}{ RESISTÊNCIAS RESIDUAIS - EBS } \\
\hline & \multicolumn{2}{|c|}{$\delta=0,5 \mathrm{~mm}$} & \multicolumn{2}{|c|}{$\delta=\mathbf{2} \mathbf{~ m m}$} & \multicolumn{2}{|c|}{ TCOD = $1 \mathrm{~mm}$} & \multicolumn{2}{|c|}{ TCOD $=4 \mathrm{~mm}$} \\
\hline & $\begin{array}{l}\text { Média } \\
\text { (MPa) }\end{array}$ & $\mathrm{CV}(\%)$ & $\begin{array}{l}\text { Média } \\
\text { (MPa) }\end{array}$ & CV $(\%)$ & $\begin{array}{l}\text { Média } \\
\text { (MPa) }\end{array}$ & CV $(\%)$ & $\begin{array}{l}\text { Média } \\
\text { (MPa) }\end{array}$ & $\mathrm{CV}(\%)$ \\
\hline Aço $-0,25 \%$ & 1,3 & 53 & 1,0 & 50 & 0,33 & 24 & 0,17 & 45 \\
\hline Aço $-0,375 \%$ & 1,8 & 15 & 1,7 & 26 & 0,51 & 20 & 0,27 & 36 \\
\hline Aço $-0,5 \%$ & 2,6 & 24 & 2,0 & 21 & 0,66 & 13 & 0,33 & 18 \\
\hline$P P-0,5 \%$ & 1,0 & 19 & 1,1 & 13 & 0,45 & 20 & 0,28 & 25 \\
\hline $\mathrm{PP}-0,75 \%$ & 1,5 & 6 & 1,5 & 11 & 0,54 & 7 & 0,34 & 17 \\
\hline $\mathrm{PP}-1 \%$ & 1,7 & 9 & 1,6 & 12 & 0,70 & 23 & 0,45 & 29 \\
\hline
\end{tabular}

No que diz respeito à resistência residual observa-se coeficientes de variação muito maiores que os obtidos para a tenacidade. Isto se deve ao fato da resistência residual ser um valor pontual que sofre todas as possíveis influências de variação do ensaio e que apresenta valores numéricos mais baixos que a tenacidade. Um dos fatores que afetam o coeficiente de variação da resistência residual é a variabilidade relativa do número de fibras presente na seção de ruptura, o que confere a capacidade resistente residual. Por essa razão, as fibras de aço, presentes em menor número, proporcionaram os maiores valores de coeficiente de variação para o ensaio JSCE-SF4, especialmente para os menores teores de fibras. Para as fibras de polipropileno, que apresentam maior número de fibras na seção de ruptura quando comparado com as fibras de aço, a variabilidade foi menor principalmente para o ensaio JSCE-SF4 e para o ELS. No gráfico da Figura 21 são correlacionados os resultados de resistências residuais.

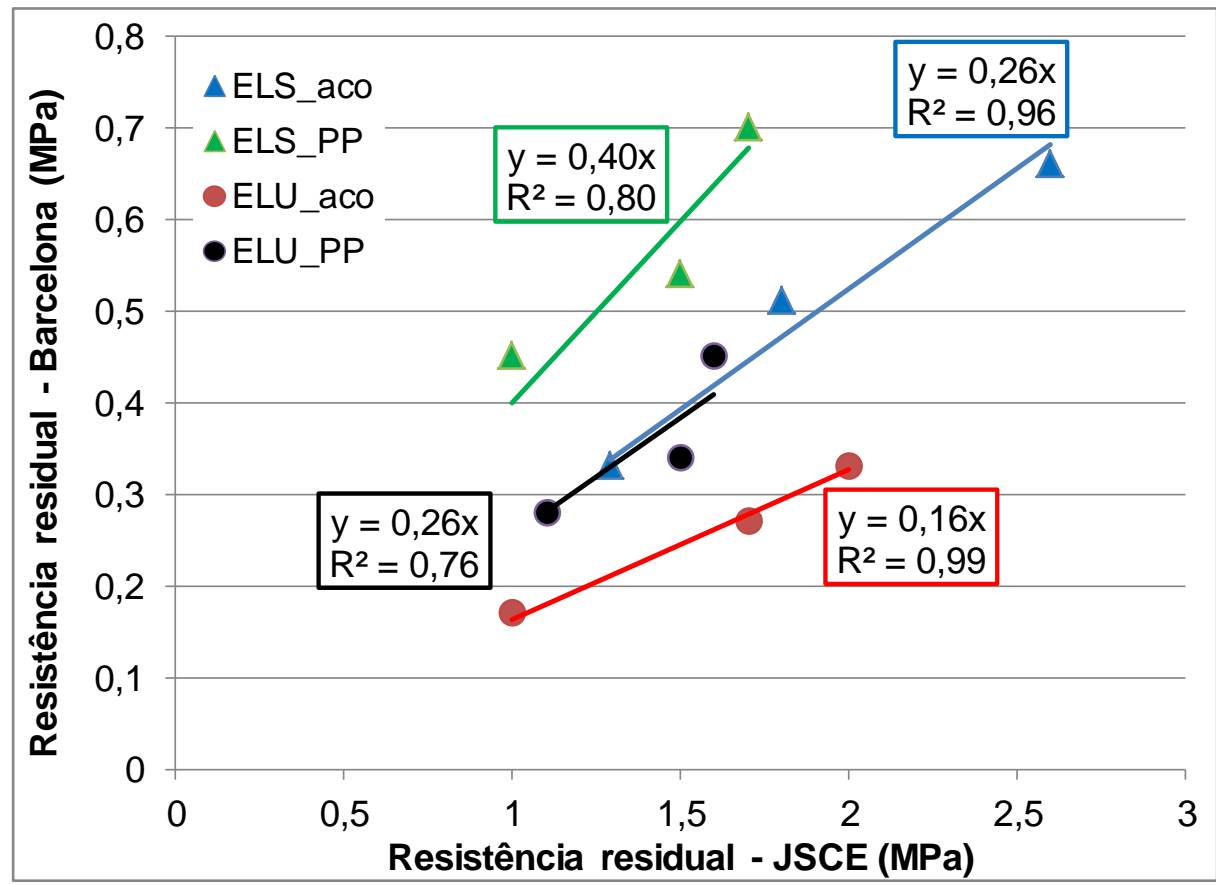

Figura 21: Regressões lineares entre as resistências residuais associadas ao estado limite de serviço (ELS) e estado limite último (ELU), obtidas para os concretos reforçados com fibras de aço e de PP.

Percebe-se pela Figura 21 que as melhores correlações foram obtidas para as fibras de aço, independente do nível de abertura de fissura. Para as fibras de polipropileno a regressão linear apresentou $\mathrm{R}^{2}$ menor. Isto pode ser associado à maior amplitude de capacidade resistente residual apresentada pela fibra de aço, $\mathrm{O}$ 
que proporcionou melhor correlação com os valores médios. Ou seja, a menor variabilidade apresentada pelas fibras de PP não colaborou para melhorar essas correlações uma vez que o aumento da resistência residual média obtido com o aumento do teor de fibras foi menor do que aquele obtido com as fibras de aço. Este diferença de comportamento já foi observada em estudos experimentais anteriores [13]. Ainda que tenham sido avaliados apenas três teores para cada fibra verifica-se que ambos os ensaios apresentam resultados correlacionáveis e permitem diferenciar comportamento dos compósitos. Cabe ressaltar que realizando uma análise da variabilidade dos dois métodos de ensaio o ensaio Barcelona apresenta, na maioria dos casos, valores menores.

\section{CONCLUSÕES}

Este artigo avaliou comparativamente os métodos de ensaio EBS e JSCE-SF4, ambos utilizando sistema aberto para controle da velocidade. A partir dos resultados obtidos é possível concluir que:

- O sistema aberto para controle de velocidade compromete a avaliação do comportamento mecânico em ambos os ensaios, principalmente para baixos teores de fibras e baixos níveis de deslocamento ou abertura de fissura;

- O ensaio EBS é um método de fácil execução, não necessita de instrumentação laboratorial complexa, mas se apresentou menos sensível a variações do teor de fibras em relação ao ensaio de flexão de vigas, especialmente nas menores faixas de consumo de fibras. Esta condição poderá favorecer melhores condições de reprodutibilidade do ensaio uma vez que o ensaio de flexão não mostrou resultados positivos neste sentido em pesquisas anteriores [16];

- Existe correlação linear entre o ensaio EBS e o JSCE-SF4 em termos de tenacidade, com coeficiente de determinação $\mathrm{R}^{2}$ superior a 0,9 , possibilitando a utilização de um ou outro sem comprometimento da avaliação desta característica;

- Existe correlação linear entre o ensaio EBS e o JSCE-SF4 em termos de resistência residual, com coeficiente de determinação $\mathrm{R}^{2}$ superiores a 0,96 para as fibras de aço e 0,76 para as fibras de polipropileno, possibilitando a utilização de um ou outro sem comprometimento da avaliação desta característica.

Dado o exposto, pode-se concluir que ambos os ensaios podem ser considerados equivalentes em termos de capacidade de avaliação e controle do CRF e correlacionáveis, havendo uma vantagem para o EBS que consiste na simplificação da metodologia de ensaio e a consequente redução de custos e potencialização de obtenção de melhores condições de reprodutibilidade. Além disso, também é um ensaio passível de ser executado em testemunhos extraídos, o que configura uma opção de avaliação de estruturas existentes executadas com este tipo de compósito.

\section{AGRADECIMENTOS}

À FAPESP - Fundação de Amparo à Pesquisa do Estado de São Paulo pela bolsa de iniciação científica concedida ao Guilherme Stoll Toaldo.

\section{BIBLIOGRAFIA}

[1] DI PRISCO, M., PLIZZARI, G., VANDEWALLE, L., "Fibre reinforced concrete: new design perspectives", Materials and Structures, v. 42, n.9, pp. 415-425, 2009.

[2] FIGUEIREDO, A. D., Concreto reforçado com fibras, Tese de Livre-Docência, Escola Politécnica, Universidade de São Paulo, São Paulo, SP, 2011.

[3] THE JAPAN SOCIETY OF CIVIL ENGINEERS, “JSCE-SF4: Method of tests for flexural strength and flexural toughness of steel fiber reinforced concrete", Concrete library of JSCE, Part III-2 Method of tests for steel fiber reinforced concrete, n. 3, pp. 58-61, 1984.

[4] AMERICAN SOCIETY FOR TESTING MATERIALS, ASTM C1609, Standard test method for flexural performance of fiber-reinforce concrete (using beam with third-point loading), 8p, Philadelphia, 2010.

[5] EUROPEAN COMMITTEE FOR STANDARDIZATION, EN 14651, Test method for metallic fiberreinforced concrete - Measuring the flexural tensile strength (limit of proportionality (LOP), residual), CEN, 15p, London, 2007.

[6] GOPALARATNAM, V. S., GETTU, R., "On the characterization of flexural toughness in fiber reinforced concretes”, Cement and Concrete Composites, v. 17, n.3, pp. 239-254, 1995. 
MONTE, R; TOALDO, G.S.;FIGUEIREDO, A.D., revista Matéria, v.19, n.02, pp. 132-149, 2014.

[7] ASOCIACIÓN ESPAÑOLA DE NORMALIZACIÓN Y CERTIFICACIÓN, UNE 83515, Hormigones con fibras. Determinación de la resistencia a fisuración, tenacidad y resistencia residual a tracción. Método Barcelona, 6p, Madrid, 2010.

[8] PUJADAS, P., BLANCO, A., CAVALARO, S., "New analytical model to generalize the Barcelona test using axial displacement", Journal of Civil Engineering and Management, v. 19, n. 2, pp. 259-271, 2013.

[9] SALVADOR, R. P., FIGUEIREDO, A. D, "Análise comparativa de comportamento mecânico de concreto reforçado com macrofibra polimérica e com fibra de aço", Revista Matéria, v. 18, n. 2, pp. 1273-1285, 2013.

[10] MOLINS, C., AGUADO, A., SALUDES, S., "Double Punch Test to control the tensile properties of FRC (Barcelona test)", Materials and Structures, v. 42, n. 4, pp. 415-425, 2009.

[11] INSTITUT BELGE DE NORMALISATION, NBN B 15-238, Test on fibre reinforced concrete bending test on prismatic simples, Brussels, 1992.

[12] ASSOCIAÇÃO BRASILEIRA DE NORMAS TÉCNICAS, NBR 15530, Fibras de aço para concreto Especificação, 7p, Rio de Janeiro, 2007.

[13] FIGUEIREDO, A. D., et al., "Fibras plásticas como reforço de tubos de concreto. Parte 1: Caracterização tecnológica", In: Congresso Brasileiro do Concreto, 54º, 2012, Maceió, IBRACON, 2012.

[14] TIGUMAN, M. P., Estudo comparativo entre métodos de quantificação de tenacidade usando concreto reforçado com macrofibras de polipropileno, Dissertação de M.sc., Escola Politécnica, Universidade de São Paulo, São Paulo, SP, 2004.

[15] MORGAN, D.R., MINDESS, S., CHEN, L., Testing and Specifying Toughness for Fiber Reinforced Concrete and Shotcrete. In: Second University-Industry Workshop on Fiber Reinforced Concrete and Other Advanced Materials, Toronto, Canada, 1995. Proceedings. pp. 29-50.

[16] GUIMAR ÃES, M. C. N., FIGUEIREDO, A. D. Análise da repetibilidade e reprodutibilidade do ensaio de tenacidade à flexão dos concretos. In: Congresso Brasileiro do Concreto do Instituto Brasileiro do Concreto (IBRACON), $44^{\circ}$, Belo Horizonte, 2002. 